\title{
The Model T and a Peek Behind the Curtain?
}

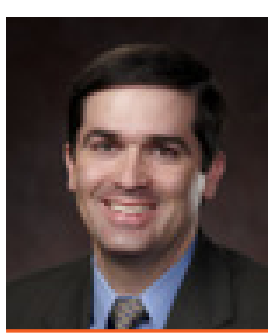

Chris Wroten, O.D., is a graduate of Southern College of Optometry (SCO) and a partner and Chief Operating Officer for the Bond-Wroten Eye Clinics. Dr. Wroten has participated in clinical research, authored clinical case reports and eyecare articles, lectured as a continuing education speaker, and presented educational posters and workshops at regional and national optometric conferences. In addition to primary eye care, his special areas of interest lie in the treatment and management of ocular disease and contact lenses.

"Change is the law of life. And those who look only to the past or present are certain to miss the future." - U.S. President John F. Kennedy

C

hange. The Future. Two similar, but complicated, concepts that many of us either fear due to uncertainty, or aggressively seek out due to the thrill of being on the cutting edge. If we're paralyzed by uncertainty, it's easy to get left behind as new and better opportunities emerge. On the flip side, it's easy to get burned by constantly chasing "the next great thing." Perhaps the most prudent course is to be constantly aware of what may lie on the horizon, while maintaining a grounded realization of potential implications for the present and future. If only things were so simple! Further complicating matters, our openness to the change the future potentially holds is affected by many variables, including our current position in life when things are going well and seemingly "on autopilot," we're often more resistant to change; but if we're down on our luck with "nothing to lose," change can be much easier to embrace.

Take, for instance, the automobile entrepreneur, Henry Ford, who revolutionized transportation around the world by innovating and "thinking outside the box." He brought the moving assembly line to the automotive industry, as well as around-the-clock factory shifts and local franchise dealerships, all while making the automobile affordable for the masses. Ford was handsomely rewarded for his innovations. At its peak, Ford Motor Company held a 50\% market share, and Henry Ford's personal net worth in today's dollars is estimated to have been $\$ 188$ Billion (for perspective, that's still \$50B more than Bill Gates and Warren Buffett today...combined!)

Yet even Ford had problems embracing change later in his career. At one point, his engineers saw the public's desire for changes to the Model $\mathrm{T}$ that had brought Ford Motor Company to the pinnacle of the automobile industry (changes that their competitors began adopting), but Henry Ford refused to modify his design because “it wasn't the Ford way" and because the intoxication of success had bred a false sense of security and an accompanying resistance to change. This myopic insistence on maintaining the status quo drove Ford Motor Company from $50 \%$ market share to the brink of closure under the same leader, within just a few years. In fact, if Henry Ford's son hadn't taken over the company and made the necessary changes, Ford Motor Company would not exist today. As the old mantra goes, "To stay still, is to fall behind."

Similarly, a myriad of innovations and technologies are poised to potentially transform the practice of eye care in the coming decades. Let's take a brief peek behind the curtain at some of these, and consider what impact they may have on the quality of care we provide our patients and how we provide it.

\section{PHARMACEUTICALS}

It's nearly impossible to track even a fraction of all the compounds that are currently in various stages of research and development in the pharmaceutical industry: from medications such as a topical broad-spectrum antiseptic (yes, an antiseptic, not an antibiotic) paired with a corticosteroid for treatment of both adenoviral and bacterial conjunctivitis in children and adults, ${ }^{1}$ to a topical, selective vascular endothelial growth factor (VEGF) inhibitor for wet age-related macular degeneration, diabetic retinopathy, and other forms of macular edema, whose efficacy rivals the currently available intravitreal anti-VEGFs. ${ }^{2}$ In addition, how about an oral compound that's a synthetic 
derivative of testosterone and which enhances endothelial cell barrier function to treat diabetic macular edema? ${ }^{3}$

In the field of glaucoma, it's been over two decades since the introduction of a truly novel class of medication, but that may soon change. Latanoprostene bunod is close to coming to market as a topical medication that breaks down into latanoprost acid, the well-established prostaglandin analog, and nitric oxide, which further enhances aqueous outflow by acting directly on trabecular meshwork. ${ }^{4}$ Further, an entirely novel class of glaucoma medications called Rho-kinase (ROCK) inhibitors is being developed by several pharmaceutical companies. ROCK inhibitors relax smooth muscle in trabecular meshwork to increase aqueous outflow, while also lowering episcleral venous pressure and further facilitating outflow, both of which are unique mechanisms of action that are not shared with any currently available glaucoma medications. Several ROCK inhibitors have also been paired with Nor-epinephrine Transport (NET) inhibitors, which suppress aqueous production, to give a triple mechanism of action. ${ }^{5}$ Combinations of ROCK and NET inhibitors paired with a prostaglandin analog to enhance uveoscleral outflow are also being developed, which could offer a quadruple mechanism of action. Compounds such as these are just a small sampling of what's in the pipeline from various ophthalmic pharmaceutical companies.

\section{DRUG DELIVERY}

Not only are new compounds being created, but drug-delivery methods are also poised to potentially undergo radical changes. Sustained-release medications in the form of next-generation fornix-based inserts, punctal plug devices, intracanalicular inserts, and medicated contact lenses are in various stages of development by multiple manufacturers. ${ }^{6,7,8}$ An ocular iontophoresis unit with a Prager shell-like device that uses a small electric current to drive medication into the eye is also being developed. ${ }^{8} 3$-D printing and nanotechnology are on the verge of drastically improving the efficacy of current and future pharmaceutical agents. What if we could prescribe medications at lower concentrations and dose them much less frequently than ever before, while at the same time drastically increasing their efficacy and reducing or possibly even eliminating unwanted side effects?

\section{ASSISTIVE DEVICES}

For our patients who have lost visual acuity, contrast sensitivity, and/or visual field, multiple companies are developing next-generation wearable devices that attach to a patient's spectacle frame, or come with a standalone frame, and audibly guide patients through the environment, and can even read labels and printed materials on command.

\section{GENE THERAPY}

No area of medicine holds more promise than gene therapy. In the U.S., the first gene therapy for inherited diseases, in this case for inherited retinal diseases, was recently approved. ${ }^{9}$ Meanwhile, a husband and wife team at the University of Washington are investigating a cure for color vision defects in primates, ${ }^{10}$ and are now moving into human trials using human recombinant DNA and a benign adenoviral vector to deliver a gene patch. While gene therapy is still a subject of debate, research is progressing rapidly in many other areas of eye care, including repairing and replacing damaged retinal pigment epithelial (RPE) cells and corneal epithelial cells. In both cases, pluripotent stem cells are harvested from a patient's own skin, then differentiated into the appropriate cell type. Imagine the possibility of curing, rather than just treating, the chronic and debilitating ocular diseases we encounter so often with our patients!

\section{OCULAR SURGERY}

Cataract surgery is also poised to have increasingly more procedures performed without general anesthesia, without the need for patients to use post-operative medications, and with multifocal intraocular lenses offering better vision (and less loss of contrast sensitivity). Numerous innovations in IOL design are being tested, including an auto-focusing IOL that uses an embedded computer chip and a self-contained battery. Glaucoma surgeries continue to become less invasive, including an ultrasound-based therapy that works much like selective laser trabeculoplasty (SLT) and newer aqueous shunt designs. The next generation of refractive surgery procedures is also emerging, such as small incision lenticule extraction (SMILE) and various corneal inlay procedures like KAMRA and Raindrop to treat presbyopia. 
Closer to home, how about a potential seismic shift in the way we refract patients? The developers of a "virtual phoropter" claim that it uses wavefront technology and computer-controlled, variable-power "virtual lenses" to drastically increase refractive accuracy versus traditional phoropters. ${ }^{11}$ In combination with newly developed manufacturing technologies, this "virtual refracting platform" would allow spectacle lenses to be precisely manufactured to levels of refractive correction previously unseen. This platform also does away with the Snellen visual acuity chart by having the patient view a high-definition photo of a real-world situation during refraction. Could we even imagine refracting without a phoropter or without a Snellen chart?

We've only scratched the surface, as the list of new and emerging eye-care technologies goes on and on. Who could predict which, if any, of these might actually be "the next great thing"? What we do know is that just a fraction of new innovations are ever able to overcome the hurdles of disappointing real-world results, potentially exorbitant cost, lackluster adoption rates, poor design, and/or inadequate marketing to attain success, and only a microscopic portion of those will truly become game-changers. However, the sheer volume of innovations in the eye-care pipeline assures that there will be some game changers, so we would do well to remember the young Henry Ford, who embraced change, who innovated, and who adopted technology to improve the quality of life for those around him, and not follow the lead of the old Henry Ford, who fell behind and nearly ruined his company with a futile and myopic stubbornness to maintain the status quo in the face of progress.

Let's not fear what's behind the curtain, but rather honestly vet each innovation and advocate to protect patients from those that don't meet standards of care, while finding ways to embrace and appropriately implement new technologies and treatments that enhance our patients' quality of life and expand the scope of care we provide. If we do, the future of eye care is bright indeed!

\section{REFERENCES}

1. Clement C, Capriotti JA, Kumar M, et al. Clinical and antiviral efficacy of an ophthalmic formulation of dexamethasone povidoneiodine in a rabbit model of adenoviral keratoconjunctivitis. Invest Ophthalmol Vis Sci 2011 Jan 21;52(1):339-44.

2. Hussain RM, Ciulla TA. Emerging vascular endothelial growth factor antagonists to treat neovascular age-related macular degeneration. Expert Opin Emerg Drugs 2017 Sep;22(3):235-46.

3. Stewart MW, Flynn HW Jr, Schwartz SG, Scott IU. Extended duration strategies for the pharmacologic treatment of diabetic retinopathy: current status and future prospects. Expert Opin Drug Deliv 2016 Sep;13(9):1277-87.

4. Weinreb RN, Liebmann JM, Martin KR, Kaufman PL, Vittitow JL. Latanoprostene bunod $0.024 \%$ in subjects with open-angle glaucoma or ocular hypertension: Pooled Phase 3 study findings. J Glaucoma 2017 Nov 30. [Epub ahead of print]
5. Ren R, Li G, Le TD, Kopczynski C, Stamer WD, Gong H. Netarsudil increases outflow facility in human eyes through multiple mechanisms. Invest Ophthalmol Vis Sci 2016 Nov 1;57(14):6197-209.

6. Lusthaus JA, Goldberg I. Emerging drugs to treat glaucoma: targeting prostaglandin $\mathrm{F}$ and $\mathrm{E}$ receptors. Expert Opin Emerg Drugs 2016;21(1):117-28.

7. Hui A, Willcox M. In vivo studies evaluating the use of contact lenses for drug delivery. Optom Vis Sci. 2016 Apr;93(4):367-76.

8. Chen H. Recent developments in ocular drug delivery. J Drug Target 2015;23(7-8):597-604.

9. Campa C, Gallenga CE, Bolletta E, Perri P. The role of gene therapy in the treatment of retinal diseases: a review. Curr Gene Ther 2017 Nov 16.

10. Neitz M, Neitz J. Curing color blindness-mice and nonhuman primates. Cold Spring Harb Perspect Med 2014 Aug 21;4(11):a017418.

11. http://www.digitalvisionsystems.com/technology.html

\section{White $\mathrm{Op}$}

For a digital copy: www.whiteop.ca/wos.pdf For a print copy please contact us by phone or email.

1-800-661-1562_orders@whiteop.ca

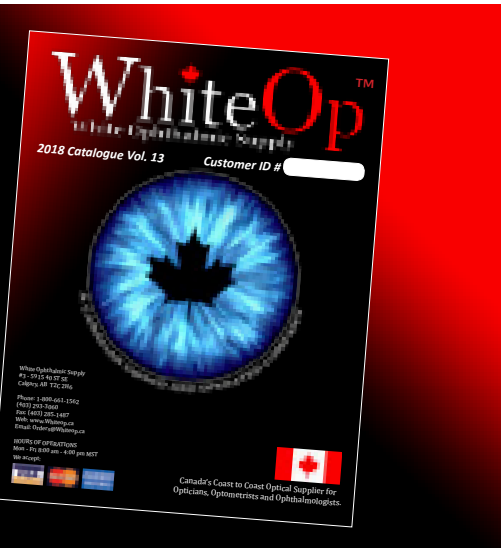

